\title{
RACISMO COMO VERBALISMO? DELINEAMENTOS PARA COMPREENSÃO DA AQUISIÇÃO DO RACISMO ENTRE CEGOS CONGENITOS
}

\author{
RACISM AS VERBALISM? DESIGNS FOR UNDERSTANDING THE \\ ACQUISITION OF RACISMO AMONG CONGENITALLY BLIND
}

\author{
Sandra Leal de Melo Dahia \\ Universidade Federal do Amazonas, Manaus, Brasil
}

\begin{abstract}
RESUMO
$\mathrm{O}$ artigo discute a questão da aquisição do racismo e do preconceito racial em crianças cegas congênitas. Está parcialmente fundamentado na perspectiva do antropólogo Lawrence A. Hirschfeld, estudioso da dimensão cultural da vida mental, pela ênfase que confere à linguagem na formação de conceitos raciais, em detrimento de indicadores visuais. O cerne do artigo reside em considerar algumas possibilidades alternativas para a construção de conceitos raciais e para a vivência do fenômeno do racismo que ora apontam para um padrão próprio aos cegos, ora apontam para um padrão semelhante ao dos videntes ou, ainda, para o mero artificialismo na vivência do racismo. Para esta alternativa, torna pertinente a introdução de uma discussão sobre relações de poder entre cegos e videntes numa sociedade visual, onde se observa que as condições sociais influenciam significativamente. O verbalismo se constitui num processo que parece acentuar a condição de subordinação dos cegos.
\end{abstract}

Palavras-chave: construção de conceitos raciais; racismo; cegueira congênita; relações de poder; verbalismo.

\begin{abstract}
This article discusses the issue of the acquisition of racism and racial prejudice in children with congenital blindness. This study was partially based on the perspective of the viewpoint of the anthropologist Lawrence A. Hirschfeld, who has researched cultural dimension of the mental life through emphasis on the role of language on the development of racial concepts, at the expense of visual indicators. The core of the study stands on considering alternative possibilities for shaping racial concepts and experiencing racism which, which at times suggest a pattern unique to the blind and, at others, one similar to the sighted, and yet occasionally evoke the mere artificiality of the experience of racism. Under this premise, the article finds it pertinent to introduce a discussion about power relations between the blind and the sighted in a visual society, whereby the social context associated with blindness significantly influences. Verbalism becomes thus a process which appears to accentuate the subordinate status of the blind.
\end{abstract}

Keywords: shaping racial concepts; racism; congenital blindness; power relations; verbalism.

\section{Introdução}

O presente artigo se volta para um tema de extrema complexidade que relaciona racismo e preconceito racialà cegueira congênita. A própria tentativa de efetuar qualquer articulação entre as questões propostas causa grande estranhamento. Isso porque há uma intuição comum de que as manifestações do racismo e do preconceito racial requeiram a percepção visual como fator desencadeante. E como consequência, mesmo considerando a viabilidade e pertinência dessa proposta temática, duvida-se intensamente da genuinidade da experiência do fenômeno entre cegos congênitos. No Brasil, onde, segundo Oracy Nogueira (1985), vigora um preconceito racial de marca, os referentes visuais de identificação e reconhecimento racial parecem assumir grande relevância. À percepção de alguns indicadores meramente físicos como cor da pele, cor e textura de cabelos, características faciais e outros aspectos morfológicos são acionadas associações simbólicas potencializadoras de práticas discriminatórias que alimentam o imaginário racista, dando substancialidade e realidade a variadas identidades raciais. Parece que à visão é concedida posição privilegiada no cenário de discriminações raciais. Esse é o contexto cultural que permeia as relações sociais no Brasil, de cegos e de videntes. Como, então, pensar a questão da percepção racial, considerando a perspectiva de cegos congênitos, sujeitos que constroem seus conceitos sobre o mundo privados de uma relevante fonte de captação e identificação racial? Embora a percepção tátil seja a indicação da viabilidade de outros referentes para a percepção direta de distinções raciais físicas, a 
impossibilidade da apreensão da cor pode sugerir a existência de distintos padrões na vivência do racismo, a origem exclusivamente discursiva desse - neste caso, conclui-se que a percepção visual não ocupa um papel central na ocorrência do fenômeno - ou mesmo o mero artificialismo da experiência entre cegos, o que remeteria a discussão para o âmbito teórico das relações de poder. O presente artigo intenciona suscitar reflexões em torno dessas possibilidades.

\section{A prevalência do discurso sobre indicadores perceptivos na construção de conceitos raciais}

Os estudos sobre a questão racial, embora tenham suscitado muitas pesquisas, apresentam resultados bastante controversos. De um modo geral, duas grandes perspectivas nos estudos sobre raça se contrapõem: uma psicológico-universalista, enfatizada, sobretudo, por psicólogos cognitivos, se volta para processos psíquicos subjacentes aos conhecimentos raciais e outra, comparativa e interpretativa, objeto da atenção de sociólogos, antropólogos, etc., compreende o conceito de raça como consequência concreta de processos sociais e históricos.

A abordagem psicológica concebe a ideia de raça como resultante da forma pela qual a informação é organizada e processada. Categorizações do mundo natural e social, a partir das diferenças e similaridades percebidas, consistem num processo cognitivo de simplificação da realidade complexa para torná-la mais inteligível. Tal processo de categorização favorece e possibilita, a partir das categorias naturais e sociais estabelecidas, uma extensão do conhecimento para captar novas similaridades não óbvias em circunstâncias não familiares. O modo como a informação humana é processada em categorias é um subproduto do pensamento e parece dispensar a interferência de fatores contextuais. Com base nessa abordagem, alguns autores sugerem que categorias como raça e gênero possuem características físicas salientes, que permitem uma aproximação com categorias naturais. Porém, em contraste com as inócuas inferências produzidas por categorias naturais, essas deduções ou simplificações cognitivas de caráter social - também chamadas de estereótipos - podem favorecer a formação do preconceito social. Nesse sentido, numa sociedade multirracial, cor da pele, forma de cabelo, entre outros, podem se constituir em características proeminentes, utilizadas, primariamente, como critérios de classificação racial baseadas em inferências equivocadas, ou seja, categorias de raça seriam objetos da extensão do conhecimento a partir de categorias naturais, já que suporiam similaridades entre elas, podendo gerar graves e indesejáveis consequências sociais e políticas.

Para a abordagem comparativa, contudo, a noção de raça seria atravessada por questões políticas, econômicas e culturais, produzidas em diferentes contextos históricos. Nesse recorte, os sistemas de pensamento racial seriam plurais e deveriam ser explicados não por causas mentais, mas em termos de relações de poder produzidas a partir de distribuições de recursos econômicos e simbólicos para diferentes grupos sociais, em circunstâncias culturais e históricas determinadas.

O antropólogo Lawrence A. Hirschfeld (1996), a partir do seu estudo sobre o desenvolvimento do pensamento infantil sobre raça, defende uma interação estreita entre as duas abordagens, tradicionalmente vistas como incompatíveis. Para ele, o conteúdo das categorias naturais e sociais e o contexto que as perpassa atuam na forma como elas são processadas. "A ideia de raça é tanto psicologicamente singular quanto historicamente específica" (Hirschfeld, 1996, p.7). A produção do conceito de raça, considerado aqui como um produto da cultura, e não como categoria oriunda do ambiente natural, é derivada, assim, tanto da capacidade conceitual humana como do contexto histórico. Segundo o autor, a distinção entre tipos humanos é realizada pelo senso comum a partir de categorias raciais que seriam consideradas naturais e duradouras, abarcando não apenas aspectos físicos, exteriores, mas também aspectos não óbvios de caráter mental e moral (Hirschfeld, 1996). Mas a ideia de raça surgiria como consequência de uma adaptação evolutiva humana, na qual a mente induziria a formação de tipos humanos para tentar entender os seres humanos como membros de grupos sociais, atribuindo-lhes características intrínsecas comuns. Estruturas mentais se formariam para capacitar os seres humanos a processar e organizar certos tipos de conhecimento e seriam compostas por aquilo que é social e historicamente valorizado. Hirschfeld sugere que somente a consideração simultânea de aspectos mentais e culturais forneceria possibilidade de explicar por que as pessoas se deslocam facilmente de categorias visuais para categorias interiores. A crença na correspondência entre características exteriores e interiores, própria à teoria racial, consiste, no entanto, no ponto mais nocivo do pensamento popular, uma vez que potencializa uma diversidade de manifestações de racismo. Segundo Hirschfeld e outros autores que adotam a visão Teórica na explicação do processo de formação de conceitos (Lomônaco, Paula, Mello, \& Almeida, 2001), a categoria raça não se desenvolveria da mesma forma de outras categorias 
sociais, mas de modo peculiar, consonante com seu domínio específico, e a partir de um enquadre cultural no qual tais categorias seriam fixadas, já que os conceitos e as teorias se formariam de acordo com cada domínio conceitual: conceitos de raças, relações de parentesco, etc., e não de uma forma geral e homogênea, conforme defendem outras abordagens. Em razão da compreensão de que ideias sobre raça e demais categorias sociais são atribuídas a propensões no processamento de informações, muitos psicólogos cognitivos se descomprometeram da formulação de teorias específicas sobre raça, embora, para Hirschfeld, o conceito de raça requeira uma análise acurada em torno de suas peculiaridades e a construção de um corpo teórico independente.

Hirschfeld (1996) minimiza a importância da percepção visual na aquisição de categorias raciais, sugerindo que a compreensão primeira da noção de raça se relaciona, mais fortemente, com a aquisição da linguagem. Ou seja, o conceito de raça para as crianças se baseia antes em informação discursiva do que em diferenças observadas. Isso não significa que esse autor ignore a importância de fatores da percepção visual para compor a noção de raça, mas, para ele: "as características físicas aparentes fornecem pistas confusas sobre a pertença racial ... mais que serem excessivamente dependentes de aparências, conceitos raciais de crianças menores envolvem codificação e obtenção de dados processados que são, em muitos modos, independentes dos fatores perceptivos" (Hirschfeld, 1996, pp.135-136). A percepção de raça, para as crianças, parece sofrer uma apreensão mais auditiva do que visual, considerando que elas se detêm inicialmente em uma formulação geral do conceito de raça para, só posteriormente, preocuparem-se como indivíduos humanos se aplicam perceptivamente a essa realidade. De acordo com Hirschfeld, a integração entre conhecimento perceptivo e conhecimento conceitual ocorre durante o final do período préescolar e o início do período escolar, momento no qual há uma justaposição das categorias verbais e categorias visuais. Essa convergência entre as duas formas de conhecimento, e não a realidade dos processos de formação dos conceitos raciais propriamente ditos, explicaria, para Hirschfeld, a ênfase que alguns pesquisadores conferem à informação perceptiva no processo de categorização racial.

\section{A emergência do preconceito racial e do racismo entre cegos congênitos}

As pesquisas sobre a origem do racismo e do preconceito racial não são conclusivas. Apesar da generalidade de alguns mecanismos de aquisição propostos - meios de comunicação de massa, associações culturais de cores, explícitas e/ou sutis pistas comportamentais de familiares e adultos, comentários de pares, valorização dos papéis sociais associados à raça, etc. -, as diferenças individuais entre crianças revelam que o processo de aquisição do preconceito racial não é automático. Conforme o viés analítico ora adotado, fatores relacionados não apenas a aspectos sociais, mas também a aspectos psicológicos precisam ser considerados para esclarecer à pergunta, ainda em aberto, sobre o porquê de algumas crianças se tornarem preconceituosas e outras não.

Grosso modo, o racismo consiste em uma ideologia fundada na crença da raça como atributo humano natural ao qual também se associariam características intelectuais e morais que serviriam para hierarquizar grupos humanos e promover diversas formas de exclusão para os grupos inferiorizados (Wieviorka, 2007). De acordo com Wieviorka, o próprio conteúdo do racismo, sobretudo do racismo científico que se estabeleceu a partir do séc. XIX, sustenta como critérios de classificação racial características fenotípicas que se manifestam à observação (2007, p. 24). Essa concepção teve grande penetração na composição da forma predominante de racismo encontrado no Brasil e tributou ao olhar o mérito de primeiro instrumento de identificação racial. Oracy Nogueira (1985), em seu livro Tanto Preto Quanto Branco: estudo de relações raciais, enfatiza a importância de indicadores visuais na identificação racial ao propor um modelo de preconceito racial específico para o Brasil. Denominado de preconceito racial de marca, baseia-se, sobretudo, na aparência, ou seja, na identificação de características físicas visíveis, diferentemente de países como os Estados Unidos, no qual vigora, segundo Nogueira, um preconceito racial atrelado à ideia de origem que não abre espaço para categorias intermediárias como a categoria do mestiço e se baseia num rígido e fixo sistema de classificação racial em torno de duas categorias apenas: branca ou negra. Na verdade, o pensamento racial brasileiro apresenta outras especificidades culturais relacionadas à própria identidade do país (DaMatta, 1987; Ortiz, 2003). De acordo com DaMatta (1987), a ideologia sobre a qual se fundamenta a formação do brasileiro prevê que esse seja o resultado híbrido do cruzamento de três raças: branca, negra e índia. A categoria do mestiço representaria a atribuição positiva conferida às categorias intermediárias no contexto brasileiro que cristalizariam a mediação entre o preto e o branco. Contudo, se reconheceria certa mobilidade na categoria do mestiço em função da atuação de variantes físicas como tonalidade da cor da pele, tipo de cabelo 
percebido, além de outras variantes de natureza social como dinheiro, ocupação, instrução, e assim por diante, que poderiam deslocar o indivíduo dentro de uma escala hierárquica de classificação racial - um continuum que variaria de uma posição de valência positiva extrema associada à figura do branco até uma posição de extrema valência negativa, caracterizada pela figura do negro. Essa dinâmica de negociação de classificação racial a partir de indicadores visuais, em grande parte associados às características físicas, encontra respaldo empírico em pesquisas sobre relações raciais desenvolvidas com crianças brasileiras (Fazzi, 2004). O estudo da socióloga Rita de Cássia Fazzi, por exemplo, teve como objetivo estudar o modo como as crianças elaboram e significam noções e experiências raciais a partir de suas relações com outras crianças e como o preconceito racial é construído nesse meio. Fazzi destacou a negatividade associada em seu estudo à categoria negro, remetendo as crianças, assim classificadas, a uma condição de inferiorização e humilhação que foram expressas em gozações e xingamentos, mas também em exclusões, nos casos de formações de eventuais pares românticos. A autora considerou, contudo, que havia certa flexibilização no processo de classificação e autoclassificação racial, mediada por vários símbolos sociais e físicos, que evitavam a classificação, consensualmente negativa, na categoria negro. A categoria morena também foi identificada na fala das crianças como uma categoria objetiva, diferente da categoria negra e dotada de um valor positivo. Também Edith Piza e Fúlvia Rosemberg, no texto Cor Nos Censos Brasileiros (2002) reafirmam o sistema múltiplo de classificação racial no Brasil, construído a partir de características fenotípicas que combinam, de forma complexa, cor da pele, em suas diferentes nuanças, traços fisionômicos, textura dos cabelos à origem regional. As autoras chamam a atenção para a importância que o quesito cor exerce sobre as relações interpessoais e como o desconhecimento sobre a proximidade ou distância entre os processos de auto ou heteroatribuição de cor, por suas implicações sociais, são aspectos que merecem um estudo mais amplo no Brasil. A despeito da relevância conferida a características físicas na ocorrência do preconceito racial no Brasil, não se evidencia sua determinação no processo, considerando a atuação de outros elementos sociais na dinâmica dessa classificação racial. Embora seja uma forma elementar de racismo (Wieviorka, 2007), o preconceito racial se caracteriza como um tipo de atitude, portanto, que não necessariamente se traduziria em ações. Isso porque nem sempre se verifica compatibilidade entre atitude e comportamento. $\mathrm{O}$ conceito de atitudes sociais evidencia três componentes elementares: o cognitivo, o afetivo e o comportamental (pensado como uma predisposição à ação), que, articulados, expressam as reações avaliadoras desfavoráveis dos sujeitos em relação a determinado objeto social, no caso específico de atitudes raciais, em relação a supostas identidades raciais (Myers, 2000). Enquanto o racismo se inscreve numa dimensão mais ampla, cultural e institucional, o preconceito, por se caracterizar como uma atitude, é um fenômeno de ocorrência individual. A despeito de suas especificidades, ambos - preconceito racial e racismo - constituem diferentes dimensões de um mesmo fenômeno.

De acordo com o sociólogo holandês Van Diyik (2008), a aquisição do racismo é um processo aprendido e amplamente discursivo, ou seja, se fundamenta numa variedade de formas de fala e de texto, numa abrangente diversidade de eventos comunicativos. É nesse contexto que a maior parte dos membros do grupo dominante aprende a ser racista. Embora não se trate de um processo automático, uma vez que cada indivíduo teria a possibilidade de, se desviando do pensamento prevalente, desenvolver perspectivas alternativas, há uma maior tendência na reprodução e manutenção do ponto de vista dominante, considerando que os membros desse grupo dominante utilizam nas suas interações cotidianas estratégias discursivas amparadas no preconceito racial para fundamentar sua dominação. Segundo Van Diyik (2008), através do discurso pedagógico, definidor da ideologia oficial mais que qualquer outro, muitas crianças recebem pela primeira vez e de forma passiva informações sobre negros, indígenas e povos de outras partes do mundo. Para outros teóricos como, por exemplo, Phyllis Katz (1982, citada por Fazzi, 2004), que se baseia nos dados de sua pesquisa, a diferenciação perceptiva é destacada como mecanismo chave no processo de aquisição do preconceito racial. Contudo, esta diferenciação perceptiva é concebida como sendo influenciada não apenas por pistas visuais distintivas, mas também por rótulos e afirmações avaliadoras de grupos. Mas, de acordo com Fazzi, que julga retificar o pensamento de Katz, "o processo básico para o desenvolvimento de atitudes hostis seria o de rotulação, associado com afirmações avaliadoras de grupo, e não o de diferenciação perceptiva" (2004, pp. 92-93). Enfatizando o papel da linguagem como mediadora de todo processo, Hischifield (1996) evidencia que a aquisição de atitudes negativas em relação a grupos raciais se relaciona antes com a interpretação da informação discursiva do que com uma possível diferenciação perceptiva. Mesmo que a diferenciação perceptiva seja reconhecida como um processo elementar para a identificação racial, por si, 
a mera constatação da diferença não explica a origem da atitude negativa em relação a tal diferença. Somente quando associada a outros critérios como inferências conceituais e avaliativas é que a diferença perceptiva parece assumir relevância no processo.

A precedência da informação discursiva sobre indicadores perceptivos visuais ganha maior relevo quando se é reportado à realidade de crianças cegas congênitas, cujo conhecimento da realidade parece, de uma forma mais patente, mediado pela linguagem. São considerados cegos congênitos indivíduos que não utilizam o recurso da visão no processo de aprendizagem e cuja cegueira é de nascença ou foi adquirida nos primeiros dois anos de vida (Amiralian, 1997). A criança cega, quando estimulada, responde prontamente, apreendendo com os seus sentidos remanescentes toda a realidade que a cerca. Quando essa realidade parece inacessível, ela busca suporte nas informações disponibilizadas por pessoas à sua volta, indagando com interesse sobre essa realidade. Para os indivíduos cegos, a linguagem assume uma função primordial no desenvolvimento conceitual, uma vez que confere uma realidade a objetos inacessíveis a experiências sensoriais possíveis ao indivíduo deficiente visual. Em determinadas circunstâncias, para Amiralian (1997), a linguagem oral substitui a realidade, assumindo diferentes funções, como a de orientação e a de classificação de características que diferenciam as pessoas, entre outras. Alguns autores fazem referência ao risco do verbalismo, ou seja, a dissociação do significado da palavra de sua matéria sensorial correspondente, uma compensação muitas vezes vista como insuficiente para a falta de representação da realidade. O verbalismo é amplamente utilizado na educação dos cegos congênitos para descrever a realidade de certos objetos e fenômenos inacessíveis à sua percepção sensorial como cor, distribuição espacial, paisagens, etc. A prática do verbalismo é objeto de muitas divergências. De um modo geral, duas tendências se desdobram na avaliação do estudo do verbalismo para cegos (Ventorini, 2009). Existem autores que atribuem uma importância ao verbalismo, no sentido em que este representaria a possibilidade de uma inclusão social efetiva na cultura da qual participam igualmente cegos e videntes, ainda que essa cultura se alicerce sobre o visuocentrismo, estando assim hegemonicamente atrelada aos códigos e às escolhas dos videntes. Nesse sentido se assume, tal como Vygotski, que: "El ciego compreende mejor el mundo de los videntes, que los videntes el mundo del ciego" (1997b, p.110). De acordo com Vygotski (2000), a construção de conceitos depende da linguagem e do pensamento, que integram informações sensoriais amalgamadas ao contexto de suas experiências e da linguagem do grupo, no qual a criança se desenvolve. Embora Vygotski chame atenção sobre a importância, sobretudo para a criança, da indissociabilidade entre material sensorial e palavra como requisito indispensável para estabelecer a relação, que ele supõe, existente entre o significado atribuído pela criança à palavra e o seu significado real considera que a palavra se sobrepõe à cegueira, uma vez que a linguagem é a principal fonte da qual o desenvolvimento retira, para cegos e videntes, seu conteúdo (1997b). Por essa razão, é válido ressaltar que a percepção visual não deve ser supervalorizada, sob pena de assumir a função de processos psíquicos superiores. Em seu artigo sobre a criança cega, Vygotski (1997b) sustenta a ideia de que, por uma questão psicológica e social, a criança cega utiliza a linguagem como meio de compensação social para alcançar, de modo efetivo, uma adequada interação social no mundo dos videntes. Na verdade, ele sugere que a redução da distância entre a realidade dos cegos e videntes representa, para os cegos, um desfecho exitoso no processo de compensação, que se caracteriza por uma maior inserção social no mundo dos videntes. $\mathrm{O}$ fracasso na compensação implicaria, ao contrário, a exigência de reconhecimento das peculiaridades dos cegos e de suas vivências e, portanto, no aprofundamento de suas diferenças em relação aos videntes. Vygotski (1997b) considera que é no plano intersubjetivo, dentro de um contexto histórico, que o sujeito se apropria da linguagem, e esse processo de aprendizagem humana é válido para todos. Ainda de acordo com essa tendência, sugere-se que a utilização dos conceitos em vários e diferentes contextos associados aos fatores maturidade e experiência poderia minimizar os efeitos negativos do verbalismo, produzindo uma real compreensão dos significados das palavras. Por outro lado, alguns autores criticam o verbalismo por acreditarem que aceitá-lo significaria, de certo modo a subjugação ao mundo dos videntes e a renúncia aos processos e imagens específicas provenientes da realidade sensorial dos cegos. De acordo com esse ponto de vista, o verbalismo ratifica a relação de subordinação dos cegos frente aos videntes, na medida em que apenas legitima a experiência que adota como referencial a visão. No dizer de uma personagem da instigante dissertação de Marcelo Farias Coutinho, é como se os cegos sofressem uma espécie de aculturação da visão (2003). Os críticos do verbalismo defendem, ao contrário, a necessidade de um conhecimento da realidade, baseado na experiência sensorial dos cegos. Por exemplo, a ideia de beleza para os cegos não deveria ser descrita com base em uma linguagem visual, refletindo uma experiência sensorial que lhes escapa e sim está fundada em um 
conceito construído a partir de seus próprios critérios sensoriais como maciez, odores, etc. Como, em geral, a descrição ou relato verbal se assenta numa perspectiva visual, considerando que os mediadores desta explicação são videntes, muitos educadores e psicólogos criticam por isto a prática do verbalismo considerando que representa ao mesmo tempo uma simplificação no processo de apreensão da realidade, bem como uma desvalorização de experiências adquiridas através de outros sentidos disponíveis para os cegos, meios de conhecimento que deveriam ser encarados como igualmente legítimos. Em sua obra, Didáctica Multisensorial de lãs Ciecias: um nuevo método para alunos ciegos, deficientes visuales, y também sin problemas de visión, Soler (1999) enfatiza a importância de uma aprendizagem mais completa e complexa, baseada na utilização de todos os sentidos. Mais do que criticar especificamente a didática empregada para cegos, que se baseia apenas no canal visual como referência para o conhecimento, critica a didática empregada na educação de crianças e adultos em geral, alicerçada numa perspectiva sensorial restritiva e empobrecedora.

\section{Racismo e cegueira: uma mera história de subordinação?}

A contribuição particular que o estudo de crianças cegas pode trazer para a compreensão do racismo e do preconceito racial reside na possibilidade de estabelecer uma comparação com crianças videntes, no sentido de evidenciar se indicadores visuais exercem influência significativa ou alguma influência na composição de tipos humanos e na construção de um posterior conceito de raça, ou se o conceito de raça dispensa a percepção visual ou, ainda, se, de fato, o racismo ou o preconceito racial é vivenciado como mero verbalismo, uma experiência artificial retirada da experiência de videntes. A complexidade na elaboração de determinados conceitos entre crianças cegas requer uma análise empírica rigorosa que investigue a sua gênese, a fim de identificar possíveis especificidades. A formação do conceito de raça, em particular, carece de uma análise aprofundada que possa fornecer respostas às inúmeras questões que o tema suscita. Seria realmente indispensável a exposição visual a pessoas racialmente diferentes para compreensão do conceito de raça? Ou essa exposição tem apenas um papel auxiliar no processo de identificação racial? No contexto perceptivo das crianças cegas congênitas, o jogo de negociação, típico do preconceito racial à brasileira, que relativiza a importância de determinadas características raciais em função de diferentes indicadores, é vivido integralmente, ou deixa de fora fatores mais visíveis como cor da pele, mesmo participando indiretamente de outros códigos sociais no processo de avaliação racial? Talvez o conceito de verbalismo se aplique de maneira mais contundente a essa realidade, considerando que o fator tonalidade da pele, catalisador de diferentes e sutis classificações raciais, não é passível de apreensão direta para uma criança cega. A prevalência do discurso como via de acesso às categorizações socialmente significadas é uma forte possibilidade, contudo, é importante pesquisar se existe uma forma mental de categorização social de tipos humanos sem a percepção visual? Seria razoável supor uma representação mental própria e exclusiva aos cegos para categorizar tipos humanos? Em suma, desenvolveriam os cegos congênitos processos peculiares que reunissem relações distintas na sua elaboração teórica ou seria um processo ancorado, exclusivamente, na realidade dos videntes? O racismo tal como é conhecido, apesar de sua pluralidade de manifestações, parece ter se erigido atrelado a uma concepção centrada na visão. Trata-se, então, de um fenômeno relacionado diretamente à realidade dos videntes, de suas escolhas? Qual seria, então, o papel dos cegos nesse caso? Seriam meros reprodutores das concepções dominantes ditadas pelos videntes? Sua socialização seria, por acaso, um processo de mera subordinação ao ponto de vista dos que enxergam? $\mathrm{Na}$ verdade, a tentativa de responder a essas e muitas outras indagações constitui uma tarefa duplamente difícil, levando-se em conta a dificuldade de comunicação entre universos tão diversos, como os constituídos por crianças e adultos e por cegos e videntes. Encaradas do ponto de vista da etnometodologia, essas dificuldades servem para explicar por que não apenas a lógica adulta se mostra imprópria para a interpretação da realidade das crianças, como também a competência da visão se torna inadequada para a interpretação da ação e da fala de cegos congênitos. O que significa organizar a percepção do mundo sem o sentido da visão? A perda para os videntes se produz pela impossibilidade de perceber a realidade sem a visão. Não é aceitável adotar a lógica de considerar que tal problema seja passível de uma solução pela tomada de algumas medidas mecânicas de tapar ou fechar os olhos como se aí se encerrasse a possibilidade de mudar a condição humana frente ao mundo e, em consequência, a forma de apreendê-lo e organizá-lo. Assumir as diferenças entre tais realidades é condição primeira para uma aproximação do universo de tais sujeitos, de modo a resgatar e dialogar com os sentidos construídos por eles próprios, a partir das peculiaridades de sua organização e de sua estruturação perceptiva. Seguindo essa linha interpretativa, algumas pesquisas indicam que a linguagem das crianças cegas não apenas expressa 
a perspectiva dos que enxergam, mas reflete uma elaboração conceitual da realidade genuína, baseada na experiência fornecida por seus mecanismos sensoriais intactos e na sua forma particular de organizar sua apreensão do mundo. Ou seja, a linguagem produz realidades, no sentido de que permite que significados novos sejam construídos diferentemente do seu significado original. Conforme o relato de Amiralian, os resultados da pesquisa realizada por Anderson e Olson indicam que a linguagem das crianças cegas expressa um conhecimento próprio, construído a partir das experiências com seus sentidos remanescentes (Amiralian, 1997, p.45). Isso porque, de acordo com Vygotsky (1997a), o indivíduo cego não é apenas um indivíduo normal com menos funções, há aí uma diferença de qualidade. $\mathrm{O}$ referido autor afirma que o desenvolvimento da criança cega se relaciona mais com as consequências sociais da cegueira em um mundo centrado na visão do que à cegueira propriamente dita. O meio social parece impor certas restrições à linguagem da criança cega, e particularmente, a uma forma de ser dos indivíduos cegos, considerando que se esses vivessem num mundo composto apenas por indivíduos cegos emergiria, como nos faz refletir Vygotski a partir de Bürklen (1924, citado por Vygotsky, 1997a), uma nova personalidade, uma nova forma de conhecer. Por que não dizer, talvez um novo preconceito racial, um novo racismo? Ainda mais porque, em geral, aquele que medeia o conhecimento da criança na explicação dos conceitos é um indivíduo vidente centrado, portanto, em sua realidade sensorial visual. Contudo, a compreensão do verbalismo como uma questão exclusiva da realidade da educação dos cegos ganha aqui o status de problema. A ideia de verbalismo postula que a falta de uma experiência direta de certas realidades produz um significado vazio de uma compreensão real, gerando, ao contrário, uma compreensão abstrata desvinculada de sua experiência sensorial concreta e fundada na experiência sensorial de outros. Em síntese, um significado mediado pela compreensão do outro e pela sua forma particular de interpretação da realidade. Tal consideração, no entanto, pode adquirir um novo desdobramento em sua análise, tendo em vista que nenhum conhecimento humano da realidade ocorre de forma pura, descolado de outras interpretações, mas é mediado por um sistema de crenças e padrões perceptivos que filtram a percepção e o entendimento do mundo exterior. $\mathrm{O}$ mundo que se pensa perceber espontaneamente e sensorialmente é mediado pelo olhar dos outros, diacronicamente e sincronicamente. Trata-se, portanto, de uma ilusão supor um processo único na apreensão do mundo. Como então é possível compreender o processo de apropriação do mundo vidente? Por um acaso, ele se dá descolado de outras visões sociais sobre a realidade? É possível um conhecimento genuíno da realidade sem o recurso de uma interpretação? Em outras palavras, é possível um conhecimento imediato sobre a realidade? Nesse caso não se estaria falando de níveis ou graus diferentes de verbalismos? Por que o verbalismo somente é deslegitimado quando se refere aos cegos?

Essa questão parece refletir uma dimensão política subjacente a essas citadas relações sociais que dinamizam um exercício de dominação traduzido em evidentes vantagens simbólicas para os videntes. Tal relação dessimétrica se funda na percepção social da deficiência como única categoria possível para compreensão dos indivíduos cegos, uma vez que sua deficiência, socialmente significada, acaba por, subliminarmente, se estender a outras áreas constitutivas de sua subjetividade. Segundo Amiralian (1997), usualmente o cego é visto, ou mesmo definido, como aquele dotado de uma limitação perceptiva ou portador de deficiência sensorial - a ausência da visão - que o restringe em suas possibilidades de apreensão do mundo externo. O referencial de análise, invariavelmente, é a perspectiva do indivíduo que enxerga, a partir de um enfoque comparativo. Nesse viés analítico, os cegos são inscritos como definitivamente deficientes e inadequados em um mundo no qual à visão é conferido um papel de legitimadora da própria realidade. Somente o olhar dos videntes concede objetividade à percepção, eliminando as incertezas subjetivas dos olhares cegos. O domínio do olhar de quem enxerga, de uma sociedade vidente, intimida e marginaliza a percepção daquele que não vê. Esse aspecto expressa uma sutil, embora eficiente, faceta do fenômeno da exclusão social. Como um processo complexo e multidimensional, a exclusão social envolve não apenas fatores objetivos, mais relacionados à realidade material, mas fatores de ordem simbólica - uma gama de fenômenos significativos como ações, manifestações verbais, textos, entre outros (Thompson, 1995), que expressam complexos processos de valorização social, produzindo admiração, rejeição, enfim, avaliação entre indivíduos e grupos sociais. $\mathrm{Ou}$ seja, às formas simbólicas são atribuídos diferentes tipos de valor, como consequência da dinâmica dos contextos sociais nos quais elas se inserem. Trata-se de um processo, muitas vezes, conflitivo, uma vez que os contextos sociais podem estar estruturados de maneiras variadas em função do tipo de relações de poder que aí se estabelecem entre os indivíduos. Grosso modo, o poder, para John B.Thompson (1995), consiste na capacidade de um indivíduo ou grupo de realizarem seus objetivos ou agirem em favor destes, 
mas o exercício desse poder depende da posição que esse indivíduo ou grupo ocupa em um campo social e dos recursos materiais ou simbólicos disponíveis e resultantes dessa localização. Em consequência disso, indivíduos e grupos são investidos de diferentes graus de poder, caracterizando, portanto, diferentes tipos de relações sociais. Quando determinados indivíduos são sistematicamente expropriados por outros de suas capacidades de agir em favor de seus próprios objetivos e interesses se estabelece uma relação assimétrica ou de dominação. Nas sociedades modernas, as bases dessas relações de dominação e subordinação podem ser estabelecidas sobre inúmeras divisões sociais relevantes como: classe, sexo, etnia, normalidade, etc. No presente caso, o foco da análise se dá em torno da relação entre indivíduos normais e indivíduos com deficiências, particularmente entre videntes e cegos, sendo os últimos, invariavelmente, percebidos como sujeitos falhos dentro de um critério social de normalidade.

De um modo geral, em suas trajetórias de vida, na busca da realização de seus objetivos e interesses, os indivíduos se baseiam muito mais em regras sociais implícitas, não estruturadas, do que em preceitos explícitos. A despeito de se inscreverem como um conhecimento prático, tais regras desempenham uma função reguladora sobre as ações sociais, consolidando padrões de interação social. Contudo, elas não possuem um caráter rígido, pois no próprio processo de sua aplicação se tornam passíveis de mudanças e ressignificações. A manifestação de dessimetria entre os poderes, reconhecida nos contextos sociais, pode ser identificada e reproduzida através de diferentes estratégias de valorização simbólica. Pelo menos duas estratégias de valorização simbólica podem ser tomadas de empréstimo dos estudos de Pierre Bourdieu (2009) e de Thompson (1995) como demarcadoras de certas posições sociais e ilustrativas da relação proposta. É importante salientar que essas estratégias simbólicas não se constituem em construções fixas, considerando que os indivíduos e grupos sociais estão permanentemente envolvidos no processo de criação de novas estratégias que favoreçam suas posições de dominação e frustrem os poderes alheios na medida em que esses representem uma ameaça real à sua condição de superioridade. Desse modo, mas não apenas desse, a posição dos deficientes visuais tem sido, com pequena variação histórica, uma posição de subordinação. Sem negar a importância física do sentido da visão, destacase aqui, sobretudo, a sua importância simbólica que exagera as condições objetivas de suas implicações e consequências sociais. Do ponto de vista do universo vidente, uma estratégia típica na relação com os cegos que merece destaque é a condescendência, uma variante sutil da dominação que traduz um misto de sentimentos ambivalentes de aparência positiva. Tratase de uma posição bem definida que ratifica uma condição de superioridade de um modo não ostensivo. A condescendência se traduz em simpatia, comiseração e certa dose de admiração aos feitos realizados pelos cegos que se manifesta em excessos de elogios, mas que, em última instância, serve para encobrir o propósito, não consciente, de mantê-los numa condição de desvantagem. É assegurado um distanciamento cordial entre os polos da relação, a fim de não permitir uma proximidade recíproca capaz de por em questão os termos assimétricos dessa relação. Por outro lado, a estratégia de resignação respeitosa constitui uma estratégia correspondente da condição de subordinação dos deficientes visuais e representa o reconhecimento da superioridade do mundo vidente, através da legitimidade que se concede ao seu ponto de vista, ao seu discurso, à sua análise, ao seu estilo de vida. Os indivíduos cegos estão permanentemente submetidos aos preceitos tácitos de funcionamento social do mundo vidente que, não obstante, os relegam a uma posição marginal, não importando o que eles realizem no plano concreto. São sistematicamente desafiados a se integrarem à sociedade, sob a promessa de uma integração plena, desde que percorram e legitimem o caminho da submissão e deferência aos códigos sociais do mundo vidente. Mesmo assim, orbitando em torno da realidade dos videntes e referendando seus códigos sociais, jamais são reconhecidos como iguais. Uma diretriz estruturante na educação dos cegos tem sido a ideia de superação, que na prática tem correspondido a uma superação de sua própria condição particular frente ao outro vidente. O efeito que o discurso de superação realiza na construção da identidade de crianças cegas é possivelmente devastador. Tratase nesse caso de uma exigência de superação que corresponde, na verdade, a uma quase negação da emergência de suas próprias peculiaridades. Em vários âmbitos da vida, como na formação de conceitos, por exemplo, ressalta-se o processo sucessivo de resolução de problemas a que estão submetidos continuamente os cegos para poderem ser socialmente incluídos. $\mathrm{O}$ processamento de informações dos cegos se torna mais difícil na medida em que ele tenta integrar suas experiências sensoriais particulares às experiências sensoriais expressas através da linguagem verbal dos videntes. Assim, tal processo, que se transforma em uma contínua busca de resolução de conflitos entre experiências públicas e privadas, se torna extenuante e muito pouco prazeroso para as crianças cegas. Também no âmbito das relações sociais, assumir ou partilhar um discurso racista pode representar, algumas vezes, uma mera tentativa, muitas vezes não consciente, de 
inserção social. Desse modo, o desenvolvimento da criança cega parece estar relacionado de maneira muito mais íntima às consequências sociais da cegueira em um mundo vidente do que à cegueira propriamente dita. A inclusão para os cegos parece ter um alto custo, uma vez que ela não contempla um movimento bilateral de integração social que implique uma contrapartida da sociedade vidente. Pelo contrário, sua inclusão requer um sobre-esforço de adaptação de sentido único à realidade dos videntes e de suas escolhas. Sobre este aspecto e guardadas as devidas diferenças, Maria Aparecida Silva Bento (Carone \& Bento, 2002), em seu estudo sobre os efeitos subjetivos e objetivos do branqueamento no Brasil, fornece um rico viés de análise para compreensão da relação assimétrica entre normais e pessoas com deficiência. Em seu texto (2002), a autora afirma que o branqueamento consistiu numa ideologia forjada pela elite branca brasileira para encobrir seus próprios temores com a ameaça negra sobre o país, embora tenha se afigurado como um problema exclusivo do negro -- que supostamente desejaria, através da miscigenação, embranquecer. $\mathrm{Na}$ verdade, a autora chama a atenção para o silêncio dos brasileiros brancos frente à questão racial como estratégia para inscrever o tema como objeto da preocupação apenas dos negros, ocultando o fato de que se trata de um processo relacional que os implica diretamente. Segundo a autora, os brasileiros brancos, maiores beneficiários simbólicos e concretos da realidade da escravidão, não se reconhecem como parte fundamental na construção e permanência das desigualdades raciais no Brasil. Tal omissão, além de proteger seus privilégios, revela um forte componente narcísico, de autopreservação e autovalorização grupal, ao mesmo tempo em que revela um total descompromisso moral e político com o outro, o grupo de fora. Na condição de grandes beneficiários simbólicos da herança do conceito de normalidade, os normais, que se colocam como padrão de referência da própria condição humana tendem, através do seu descaso com os deficientes, a entravar a implementação de medidas que os beneficiem materialmente e simbolicamente, emitindo, assim, a subliminar mensagem de que tal matéria não lhes diz respeito, é fonte de constrangimentos e desconfortos e, portanto, deve ser abordada pelos reais interessados.

Resta, não obstante, a esperança, pois, a despeito de seu relevante papel na reprodução das relações sociais assimétricas, as estratégias simbólicas não são fixas, elas são instrumentos para que os indivíduos ponham em prática seu poder em busca da realização de seus objetivos e, ao mesmo tempo, são reflexos desses poderes. São, por isso, alvos de disputas, interesses contrários e conflitos. O processo é intensamente dinâmico e contraditório, capaz de ser perpassado por novas e diferentes possibilidades de produção, interpretação, reinterpretação e recepção de sentidos que questionem os sentidos estabelecidos e mantidos no interesse de muitos. Até se chegar aí, contudo, há um longo percurso...

\section{Conclusão}

Este estudo suscitou reflexões em torno da consideração de dois fenômenos complexos de difícil articulação. A intenção precípua em empreender tal discussão residiu na possibilidade de seu aprofundamento teórico com a consecução futura de uma ampla pesquisa empírica na qual se possa investigar a construção de conceitos raciais em crianças cegas congênitas e suas consequências sociais. Mesmo que distintos padrões sejam identificados na gênese de tais conceitos, a discussão mais ampla sobre relações sociais, mediadas por uma dimensão simbólica, seus diferentes graus de valorização social e as relações de poder resultantes da manipulação de tais formas simbólicas permanecem como uma perspectiva de análise válida. Isso porque se trata de um tema que merece atenção em função de sua consequência sobre a realidade das interações sociais. A realidade social é uma produção complexa, permeada por uma variedade de significados dispostos em configurações específicas que precisam de interpretação. Tal como a definição de cultura de Clifford Geertz (1989), a compreensão ora adotada reforça a ideia de que o homem se encontra suspenso e enredado em teias de significados por ele mesmo tecidas, que precisam de interpretação. A despeito da importância da realidade objetiva, mas também muito em consequência dela, o universo subjetivo se constitui uma força real capaz de produzir sentimentos de completude e deficiência, de capacidade e incapacidade, de inclusão e exclusão, por fim, de felicidade e infelicidade. Experimentar uma nova produção de sentidos na qual a ideia de outro seja reinscrita como diferença, fora de um quadro hierárquico que implique dominação e subordinação, pode conduzir a emergência de novas possibilidades perceptivas que, em vez de anular variados estilos de vida, ressaltem a mobilidade própria ao universo das diferenças e as suas especificidades como, por exemplo, aquela que se relaciona com a impossibilidade dos videntes em conseguirem perceber a realidade sem a visão. Parece que, nesse enfoque, o lugar daquilo que se considerava desvantagem se desloca e destitui os videntes de certo poder, indicando a relatividade dos lugares sociais em função do referencial adotado. Visto desse modo, tudo parece uma questão de perspectiva, não parece? 


\section{Referências}

Amiralian, M. L. (1997). Compreendendo o cego: uma visão psicanalítica da cegueira por meio de desenhos-estórias. São Paulo: Casa do Psicólogo.

Bourdieu, P. (2009). O poder simbólico (12 ${ }^{\mathrm{a}}$ ed.). Rio de Janeiro: Bertrand Brasil.

Coutinho, M. F. (2003). Antão, O Insone: estudo sobre relações dialógicas entre a visão e a cegueira. Dissertação de Mestrado, Programa de Pós-Graduação em Comunicação, Universidade Federal de Pernambuco, Recife.

Carone, I. \& Bento, M. A. (Orgs.). (2002). Psicologia social do racismo: estudos sobre branquitude e branqueamento no Brasil. Petrópolis, RJ: Vozes.

DaMatta, R. (1987). Relativizando: uma introdução à antropologia social. Rio de Janeiro: Rocco.

Fazzi, R. C. (2004). O drama racial de crianças brasileiras: socialização entres pares e preconceito. Belo Horizonte: Autêntica.

Geertz, C. (1989). A interpretação das culturas. Rio de Janeiro: LTC.

Hirschfeld, L. (1996). Race in the making: Cognition, culture and the child's construction of human kinds. Massachusetts: The MIT Press.

Lomônaco, J. F. B., Paula, F. V., Melo, C. B., \& Almeida, F. A. (2001). O desenvolvimento de conceitos: o paradigma das transformações. Psicologia: Teoria e Pesquisa, 17(2), 161168.

Myers, D. (2000). Psicologia Social. Rio de Janeiro: LTC.

Nogueira, O. (1985). Tanto preto quanto branco: estudo de relações raciais. São Paulo: T. A. Queiroz.

Ortiz, R. (2003). Cultura brasileira e identidade nacional. São Paulo: Brasiliense.

Piza, E. \& Rosemberg, F. (2002). Cor nos censos brasileiros. In I. Carone \& M. A. Bento (Orgs.), Psicologia social do racismo: estudos sobre branquitude e branqueamento no Brasil (pp. 91-120). Petrópolis, RJ: Vozes

Soler, M. A. (1999). Didáctica multisensorial de las ciencias: um nuevo método para alumnos ciegos, deficientes visuales, y também sin problemas de visión. Barcelona: Ed. Paidós Ibérica.

Thompson, J. B. (1995). Ideologia e cultura moderna: Teoria social crítica na era dos meios de comunicação de massa. Petrópolis, RJ: Vozes.
Van Dijk, T. A. (Org.). (2008). Racismo e discurso na América Latina. Brasília: Unesco; São Paulo: Ed. Contexto.

Ventorini, S. E. (2009). A experiência como fator determinante na representação espacial da pessoa com deficiência visual. São Paulo: UNESP.

Vygotski, L. S. (1997a). Los problemas fundamentales de la defectologia contemporânea. In L. S. Vygotski, Obras Escogidas V: Fundamentos de Defectologia (pp. 11-40). Madrid: Visor.

Vygotski, L. S. (1997b). El niño ciego. In L. S. Vygotski. Obras Escogidas V: Fundamentos de Defectologia (pp. 99-113). Madrid: Visor.

Vygotski, L. S. (2000). A construção do pensamento e da linguagem (Psicologia e Pedagogia). São Paulo: Martins Fontes.

Wieviorka, M. (2007). O racismo, uma introdução. São Paulo: Perspectiva.

Recebido em: 27/11/2011

Revisão em: 21/10/2012

Aceite em: 09/11/2012

Sandra Leal de Melo Dahia é Professora adjunta do Departamento de Psicologia da Universidade Federal do Amazonas em lotação provisória na Universidade Federal da Paraíba. Doutora em Sociologia pela Universidade Federal da Paraíba desde 2007. Atua na Psicologia Social, principalmente, nos seguintes temas: racismo, preconceito racial e inclusão social. Endereço: Universidade Federal da Paraíba, Centro de Ciências Humanas, Letras e Artes, Campus I, Av. Contorno da Cidade Universitária, Castelo Branco, João Pessoa/PB, Brasil. CEP 58051-900. Email: sandradahia@yahoo.com.br.

\section{Como citar:}

Dahia, S. L. M. (2013). Racismo como verbalismo? Delineamentos para compreensão da aquisição do racismo entre cegos congênitos. Psicologia \& Sociedade, 25(1), 103-112. 